\title{
Arbor
}

\section{Servicios de inteligencia y lucha antiterrorista}

\section{Javier Jordán Enamorado}

Arbor CLXXX, 709 (Enero 2005), 227-246 pp.

El terrorismo, y más concretamente el yihadismo global, se ha convertido en una de las principales amenazas violentas contra la seguridad de Estados Unidos y de Europa. Como consecuencia ha pasado a ocupar un lugar prioritario entre los temas de interés de los servicios de inteligencia. Este artículo describe en un primer epígrafe las características esenciales del terrorismo yihadista, con objeto de subrayar las similitudes y diferencias que plantea en comparación con otros tipos de terrorismo. Seguidamente, analiza de qué manera la naturaleza particular de este terrorismo afecta al desarrollo de las tareas de propias de los servicios, repasando cada una de las fases del ciclo de inteligencia. Por último, termina con una serie de consideraciones sobre la adaptación del Centro Nacional de Inteligencia español a la lucha contra el yihadismo global.

La lucha contra el terrorismo se ha convertido en una de las principales misiones de las agencias de seguridad. En España los servicios de inteligencia vienen dedicando desde hace más de tres décadas un considerable esfuerzo a la prevención y lucha de esta amenaza. El protagonismo que durante este tiempo han acaparado la organización terrorista ETA y su entorno radical explica que la mayor parte los recursos humanos y materiales se hayan orientado a obtener inteligencia sobre ellos. Sin embargo, el declive de la banda y el auge que en los últimos años ha experimentado el terrorismo de inspiración islamista están motivando 
que el foco de interés se sitúe crecientemente sobre este último. Se trata de una tendencia que ya había comenzado a manifestarse desde el principio de esta década, particularmente a raíz de los atentados de Washington y Nueva York, y que se ha visto reafirmada y potenciada tras los ataques terroristas de Madrid el 11 de marzo de 2004.

Este artículo tiene por finalidad describir las características principales del terrorismo yihadista, con objeto de subrayar su singularidad en comparación con otros tipos de terrorismo. Seguidamente, y utilizando como guión las fases del ciclo de inteligencia, analiza de qué manera la naturaleza particular de este terrorismo puede afectar al desarrollo de las tareas propias de los servicios, prestando en el último epígrafe una atención especial al caso del Centro Nacional de Inteligencia español.

\section{Notas características del terrorismo yihadista global}

Son varias los rasgos esenciales de lo que actualmente se viene en llamar «yihadismo global» que permiten incluir dentro de esta misma categoría a grupos de procedencia diferente $y$, a menudo, sin conexión operativa. En los subepígrafes de este apartado se realiza una breve descripción de cada uno de ellos.

\subsection{Inspiración ideológica común: el salafismo yihadista}

La primera característica consiste en que las diversas redes que componen el entramado mundial de la yihad están animadas por una misma ideología y comparten objetivos estratégicos básicamente similares. Dicha ideología es el salafismo yihadista que se describe a continuación.

El salafismo es un conjunto de corrientes del islam que tienen en común el interés por volver a los orígenes doctrinales de la religión y al modo de vida de los primeros musulmanes, purificando el islam de las creencias y prácticas desviadas que lo han ido contaminando tras siglos de historia. El salafismo no es un fenómeno homogéneo y dentro de él existen diversas interpretaciones sobre cómo llevar a cabo esa vuelta a los orígenes. Al salafismo pertenecen corrientes tan dispares como el wahabismo, el deobandismo (que a su vez inspira a movimientos tan diferentes entre sí como la Yama'a al-Tabligh y los talibanes), los grupos vinculados con Hermanos Musulmanes y los intelectuales que en el siglo XIX admiraron los logros políticos de Occidente e intentaron aplicarlos a 


\section{Servicios de inteligencia y lucha antiterrorista}

la teoría política islámica ${ }^{1}$. Los principios ideológicos comunes a todas estas líneas doctrinales consisten en el deseo de restaurar la grandeza originaria del islam desde el punto de vista religioso y también temporal; la voluntad de reislamizar las sociedades musulmanas a partir de lo que ellos entienden como ortodoxia; la aspiración de que las estructuras políticas sean también islámicas y velen por la creación de un entorno acorde a los principios religiosos (una vuelta por tanto a la primera comunidad de creyentes donde no había una separación entre los ámbitos político y religioso); el deseo de lograr la unión de todos los musulmanes; y la voluntad de extender el islam por todo el planeta.

La concreción de estos objetivos y el modo de alcanzarlos, además del origen histórico particular de cada una de las corrientes salafistas, diferencian a unos grupos de otros. Dentro de esa variedad de interpretaciones, el salafismo yihadista es una corriente doctrinal que contempla el empleo de la violencia como un instrumento aceptable e imprescindible a la hora de alcanzar determinados objetivos. El principal ideólogo del yihadismo fue el egipcio Sayid Qutb, ejecutado por el régimen de Nasser en 1966. A partir de él otros partidarios de la yihad la convirtieron en una obligación religiosa similar a los otros cinco pilares del islam. Algunos, como el palestino Abdullah Azzam sólo la justificaron si tenía como fin defender la tierra del islam (por ejemplo de la agresión soviética en Afganistán). Otros, como el egipcio Abdesalam Faraj, la consideraron necesaria para derrocar a los gobernantes de los países musulmanes que no aplicaban la sharia. Y, finalmente, los partidarios de la yihad global promueven su empleo contra el «enemigo de lejos», es decir Occidente y más en concreto Estados Unidos, sin cuya derrota previa será imposible frenar las agresiones contra el islam y alcanzar la unión política de todos los musulmanes en un nuevo califato. Uno de los principales defensores de esta lucha a escala planetaria es el egipcio Ayman Al-Zawahiri, también promueven esta idea Abu Qatada y Osama Bin Laden² y otros predicadores e ideólogos de segundo nivel del yihadismo global.

Esta primera nota distintiva tiene una enorme relevancia a la hora de entender la magnitud del terrorismo yihadista. Por un lado se trata de una agenda política que no tiene fronteras, a diferencia de otras causas

\footnotetext{
1 Youssef M. ChoueIRI, Islamic Fundamentalism, London and Washington, Pinter, 1997.

2 Javier JORDÁN y Luisa BOIX, «La justificación ideológica del terrorismo islamista. El caso de Al-Qaida", en Javier JoRDÁN (Coord.) Los orígenes del terror. Indagando en las causas del terrorismo, Madrid, Biblioteca Nueva, 2004, pp. 145-185.
} 
terroristas limitadas a un espacio territorial concreto (por ejemplo los grupos independentistas o los partidarios de la revolución contra un determinado régimen). Por tanto la ideología yihadista puede contagiar a personas de muy variada nacionalidad, a condición de que profesen la vertiente más radical del islam. La plurinacionalidad de los voluntarios que pasaron durante los años 80 y 90 por Afganistán es una buena prueba de ello.

En relación con este primer motivo, otro factor relevante de la inspiración ideológica consiste en que el salafismo yihadista comparte muchos de los principios presentes en las otras corrientes salafistas. Este hecho hace compatible que, por una parte, haya personalidades religiosas del salafismo que condenen con claridad el terrorismo islamista, y que, al mismo tiempo, exista un trasvase de personas que militan en entornos moderados que posteriormente acaban incorporándose a grupos radicales violentos. Esta realidad se observa en los mismos ideólogos yihadistas. Por ejemplo Qutb y Azzam fueron miembros de Hermanos Musulmanes (que en su mayoría no aceptan el yihadismo global) y Ayman al-Zawahiri frecuentó en su juventud un movimiento salafí no violento llamado "La asociación de los seguidores del camino de Mahoma», aunque posteriormente lo abandonó para unirse a un grupo radical en Egip$\mathrm{to}^{3 .} \mathrm{A}$ su vez cientos de integrantes de redes yihadistas han tenido contacto previo con asociaciones islámicas que en sí mismas no promueven el terrorismo pero que son utilizadas como escalón previo y lugar de reclutamiento por los radicales ${ }^{4}$.

Por último, otro aspecto destacado de la ideología yihadista consiste en que es capaz de dotar de coherencia narrativa a pasiones de signo diverso. Es decir, a través del discurso yihadista se puede justificar la lucha contra la presencia militar de Estados Unidos en Irak, de Rusia en Chechenia o de Israel en Gaza y Cisjordania. A la vez se puede promover la rebelión contra el gobierno de Musharraf en Pakistán, de Mohamed VI en Marruecos o de la monarquía saudí en Arabia, acusando a todos ellos de ser falsos musulmanes y aliados de los infieles. Y al mismo tiempo se puede legitimar la lucha contra las minorías y los gobiernos no musulmanes en determinadas islas de Indonesia y Filipinas, o en Sudán y Nigeria. En definitiva, el yihadismo puede catalizar motivos para la vio-

\footnotetext{
3 Nimrod RAPHAELI «Ayman Rabi» Al-Zawahiri: The Making of an Arch-Terrorist», Terrorism and Political Violence, Vol. 14, No. 4, (2002), pp. 1-22.

${ }^{4}$ Marc SAGEMAN, Understanding Terror Networks, Philadelpia, University of Pennsylvania Press, 2004, pp. 118-119.
} 
lencia que poco o nada tienen que ver con la religión, pero que adquieren fuerza adicional y respaldo moral al ser interpretados desde la óptica salafista radical.

\subsection{Terrorismo como instrumento de destrucción y de presión, no de negociación}

Esta es otra de las notas fundamentales del terrorismo yihadista global. Al tratarse de una ideología maximalista, la violencia no tiene como fin obtener concesiones parciales o lograr mayor peso político en unas posibles negociaciones. Por el contrario, se trata de un empleo de la fuerza dirigido a destruir, derrocar o expulsar a los etiquetados como enemigos; sin posibilidad por tanto de arreglos intermedios y, sobre todo, sin mayores límites a la violencia que aquellos que imponen los medios materiales y los condicionantes operacionales a la hora de llevarla a cabo5. De ahí el temor justificado a que el yihadismo global pueda llegar a utilizar armas de destrucción masiva en caso de que llegara a hacerse con ellas. También tiene así explicación la ejecución de atentados tan letales como los de Washington, Nueva York, Dar al Salam, Nairobi, Bali o Madrid donde los yihadistas han segado miles o cientos de vida de un solo golpe.

Lo peor de esta característica del yihadismo es su tendencia a consolidarse en la actuación futura de sus redes. Si bien es verdad que cuando se han producido esas masacres la opinión pública mundial (musulmana y no musulmana) ha quedado espantada, también es cierto que ese tipo de acciones -sobre todo las ejecutadas contra objetivos occidentaleshan supuesto un considerable éxito en términos de movilización a favor de los yihadistas. Con ellas se ha demostrado que es posible provocar un enorme daño y condicionar o modificar la política de gobiernos considerados adversarios. Por ejemplo, tras el ataque terrorista contra el destructor USS Cole en Yemen se produjo un aumento del número de voluntarios en los campos de entrenamiento de Afganistán y se redujo durante semanas el tráfico naval militar de Estados Unidos en las aguas del Golfo Pérsico ${ }^{6}$. Los atentados del 11 de septiembre dieron a su vez un

\footnotetext{
5 Ian O. LESSER «Countering the New Terrorism. Implications for Strategy", en Ian O. Lesser, Bruce Hoffman, John Arquilla, David Ronfeldt, Michele Zanini, Brian M. Jenkins, Countering the New Terrorism, Santa Mónica, RAND, 1999, pp. 85-144.

${ }^{6}$ National Commission on Terrorist Attacks, «The 9/11 Commission Report: Final Report of the National Commission on Terrorist Attacks Upon the United States, pp. 190-192.
} 


\section{Javier Jordán Enamorado}

espaldarazo mundial a la causa yihadista y miles de radicales contemplaron con admiración a Al-Qaida por ser capaz de enfrentarse con eficacia al coloso norteamericano. Los atentados de Madrid y la apresurada retirada de las tropas españolas de Irak apenas dos meses después reforzaron también la autoconfianza de los yihadistas ${ }^{7}$.

Desgraciadamente todo parece indicar que la idea de que los «superatentados» constituyen el instrumento más válido para hacerse oír e implementar los objetivos yihadistas está firmemente afianzada en la mente de quienes contribuyen a definir la estrategia global del movimiento y de quienes planifican las acciones terroristas. En su libro Caballeros bajo el estandarte del profeta, Ayman Al-Zawahiri dice con toda claridad que es preciso llevar a cabo ataques que produzcan un número muy elevado de muertes y que tengan el mayor impacto posible sobre las estructuras del adversario pues, según él, ese es el lenguaje que entiende Occidente ${ }^{8}$. Las últimas acciones terroristas y -sobre todo- otras muchas que han sido evitadas a tiempo, prueban que efectivamente esa es la línea que los yihadistas están dispuestos a seguir.

\subsection{Estructura organizativa muy diferente de otros grupos terroristas anteriores}

En los últimos años ha sido posible conocer detalles importantes sobre la organización de Al-Qaida que no eran del todo claros en fechas cercanas a los atentados del 11 de septiembre. Por una parte se ha demostrado que, aun tratándose de una estructura con considerables dosis de descentralización -especialmente en el nivel táctico-, al mismo poseía una fuerte estructura jerárquica en los escalones más elevados, la mayor parte de ellos con base en Afganistán. Por tanto la conducta descentralizada en el día a día de las redes implantadas en otros países y de los grupos

\footnotetext{
Disponible en web: http://www.9-11commission.gov/report/911Report.pdf [consultado: noviembre de 2004].

7 Haizam Amirah, «¿Tiene Al-Qaeda una estrategia global?», Análisis Real Instituto Elcano, $\mathrm{n}^{\mathrm{o}}$ 74, 20 de abril de 2004. Disponible web en: http://www.realinstitutoelcano.org/analisis/484.esp [consultado: noviembre de 2004].

8 Puede consultarse un compendio de fragmentos de ese libro en la siguiente dirección web de la Federación de Científicos Americanos: http:www.fas.org/irp/wold/para/ayman bk.html [consultado: noviembre de 2004].

9 National Commission on Terrorist Attacks, «The 9/11 Commission Report: Final Report of the National Commission on Terrorist Attacks Upon the United States, pp. 67.
} 
asociados o financiados con Al-Qaida se combinaba con la centralización de algunas tareas concretas de financiación o propaganda, y de determinadas operaciones terroristas de gran magnitud, como fueron los atentados contra las embajadas de norteamericanas en Kenia y Tanzania o los preparativos que rodearon los atentados de Washington y Nueva York ${ }^{9}$.

Sin embargo, la relevancia de la jerarquía interna del núcleo central de Al-Qaida, o del juramento de lealtad a Osama Bin Laden por parte de sus miembros y líderes de grupos asociados, parece haber disminuido sensiblemente en el tiempo transcurrido desde el inicio de la campaña norteamericana en Afganistán. En estos tres años la organización terrorista, que ejecutaba operaciones propias y hacía de franquicia para la actuación de otros combatientes de la yihad, ha sufrido un intenso desgaste como consecuencia de la pérdida del santuario talibán, y de la muerte o captur ra de más de la mitad de sus miembros de alto nivel. No obstante el eclipse de la organización directamente controlada por Bin Laden ha coincidido con un incremento también muy marcado del número de acciones terroristas (o intentos fallidos de ellas) vinculadas ideológicamente a la yihad global, del volumen de comunicados (que se ha cuadriplicado) y de un flujo ininterrumpido de nuevos voluntarios dispuestos a ingresar en este tipo de redes o marchar a combatir en Asia Central o Irak ${ }^{10}$.

La diferencia entre el antes y después del 11 de septiembre no se encuentra sólo en el auge del yihadismo global (que se ha visto favorecido por aquellos atentados y por la reacción ante la política norteamericana respecto a Afganistán, Israel e Irak), sino también en el cambio de la estructura organizativa del yihadismo a partir de aquella fecha. Rohan Gunaratna afirma que inicialmente Al-Qaida fue una organización y que actualmente se ha convertido en un movimiento ideológico. Esta es una buena forma de expresar la eclosión y extensión del yihadismo global en poco más de una década, ya que -hasta finales de los años 80- los objetivos de quienes creían combatir una guerra santa en nombre del islam se limitaban en la mayor parte de los casos a sus respectivos países. Era una yihadismo local o regional, pero no global ${ }^{11}$.

Al-Qaida (entendida como la organización controlada directamente por Bin Laden y sus más estrechos colaboradores) desempeñó un papel crucial e histórico en la emergencia y difusión a nivel mundial del yiha-

\footnotetext{
10 Rohan Gunaratna, «The Post-Madrid Face of Al Qaeda», The Washington Quarterly, Vol. 27, № 3, (2004), pp. 91-100.

11 Javier JoRDÁn, Profetas del miedo. Aproximación al terrorismo islamista, Pamplona, EUNSA, 2004, pp. xxx
} 
dismo. Pero a día de hoy su protagonismo está disminuyendo como consecuencia de los éxitos logrados por la lucha antiterrorista y a causa también del mayor relieve que están adquiriendo otras redes yihadistas que comparten objetivos estratégicos similares pero que no se encuentran vinculadas operativamente con el núcleo central de la organización ${ }^{12}$.

Estas nuevas redes se están formando a partir de relaciones personales ya existentes o nuevas (pero establecidas en contextos que favorecen la confianza mutua, por ejemplo a partir de intermediarios seguros), y son esos vínculos interpersonales los que caracterizan su modo de proceder. Se trata de grupos de individuos que coinciden ideológicamente, que mantienen algún tipo de contacto entre sí, que colaboran esporádicamente en tareas de proselitismo, propaganda, financiación y apoyo logístico, y que eventualmente pueden sumarse a la preparación y ejecución de una acción terrorista. Más que una organización de corte burocrático (con roles muy definidos y una entidad externa a los individuos que la componen), las redes de la yihad global son en muchos casos grupos de amigos y conocidos que se prestan ayuda mutua y que en determinados momentos se embarcan en proyectos de diferente naturaleza (logística o directamente violenta) ${ }^{13}$. Este diseño organizativo -mucho más descentralizado que el que mantuvo Al-Qaida en los años 90- plantea numerosos problemas en materia de lucha antiterrorista pero también disminuye la capacidad de llevar a cabo acciones tan coordinadas y espectaculares como los atentados del 11 de septiembre. El potencial destructor de las redes de este tipo (por ejemplo las desarticuladas en octubre-noviembre de 2004 en España y Holanda) dependerá de su habilidad y de la suerte a la hora de adquirir medios con los que atentar, y de que sean capaces de descubrir vulnerabilidades y ventanas de oportunidad en la estructura política, económica y social de sus potenciales objetivos.

\section{El terrorismo islamista en el ciclo de inteligencia}

Al tratarse de un terrorismo de naturaleza diferente al de otros grupos que han existido con anterioridad (tanto en su ideología, su modo de

\footnotetext{
12 Rohan Gunaratna, "Al-Qaeda adapts to disruption», Jane's Intelligence Review, February 01, 2004.

${ }^{13}$ Marc Segeman, Understanding Terror Networks, Philadelpia, University of Pennsylvania Press, 2004; Brad MCALLISTER, «Al Qaeda and the Innovative Firm: Demythologizing the Network", Studies in Conflict \& Terrorism, Vol. 27, (2004), pp. 297-319.
} 
proceder y su estructura organizativa) resulta evidente la necesidad de adaptar los procedimientos de inteligencia orientados a la política antiterrorista. Con el fin de sistematizar la exposición, se utilizará a modo de guión la manera como que afecta la lucha contra el yihadismo global a cada una de las fases del ciclo de inteligencia.

\subsection{Fase de Dirección}

El terrorismo yihadista global se ha convertido para muchos servicios de inteligencia en lo que la comunidad norteamericana denomina hard target, un asunto de especial interés. Los atentados del 11 de septiembre en Washington y Nueva York y -dos años y medio después- los de Madrid han situado a este tipo de terrorismo en el apartado de prioridades de los servicios de ambos lados del Atlántico. Las razones son obvias. Por un lado, el interés de evitar una tragedia similar en el propio territorio y, por otro, la oportunidad para los países europeos (y para otros gobiernos fuera de Europa) de mejorar la cooperación con Estados Unidos, que ha convertido esta cuestión en uno de los puntos más destacados de su agenda exterior.

Sin embargo, con anterioridad a 2001 el yihadismo global ocupó un lugar mucho menos relevante en la lista de prioridades de los servicios de inteligencia occidentales. En Estados Unidos no se tomó conciencia del peligro real que significaba Osama Bin Laden y su red terrorista hasta los atentados contra las embajadas de Kenia y Tanzania en agosto de 1998; es decir, casi una década después de la creación de Al-Qaida ${ }^{14}$. A partir de entonces se intensificó gradualmente la alerta y se produjo un incremento limitado de recursos, pero no se llevaron a cabo reformas profundas dentro de los servicios y de la relación entre ellos con el fin de adaptar la comunidad de inteligencia a una amenaza completamente distinta a la que había representado durante más de cuarenta años la Unión Soviética. La lectura del informe de la Comisión Nacional sobre los ataques terroristas del 11-S ofrece la imagen de que las agencias norteamericanas asumían con cierto fatalismo la posibilidad de que Al-Qaida acabase atentando en territorio estadounidense ${ }^{15}$. El yihadismo global era una prioridad importante, entre otras, pero las inercias del pasado y las

14 National Commission on Terrorist Attacks, «The 9/11 Commission Report: Final Report of the National Commission on Terrorist Attacks Upon the United States, p. 122.

15 Ibid. p. 182. 
barreras institucionales dificultaban que esa relevancia afectara sustancialmente al resto del ciclo de inteligencia y a la estructura y funcionamiento de la propia Comunidad.

En Europa la atención que recibía el yihadismo antes de otoño de 2001 variaba según el país. Posiblemente la comunidad de inteligencia francesa era la más avanzada y consciente en este aspecto. Además de que las personas de origen magrebí suponen aproximadamente un $10 \%$ del total de la población del país y de que existe constancia de que en su seno llevan actuando desde años grupos islamistas radicales ${ }^{16}$, en 1995 su territorio fue escenario de una campaña de atentados ejecutados por el GIA argelino y una red local de inmigrantes de segunda generación ${ }^{17}$. Por otra parte, a finales de 2000 la policía alemana detuvo una célula en Frankfurt que estaba preparando varios atentados masivos en Estrasburgo $^{18}$. Todo ello llevó a que el gobierno francés convirtiese en una prioridad la lucha contra este tipo de terrorismo.

En otros países europeos la atención que recibía el yihadismo se encontraba en función del sentimiento de amenaza que este suponía, y de la presencia o no de grupos radicales en el territorio nacional. En el caso español, la desarticulación de redes yihadistas de origen argelino se inició a mitad de la década de 1990, pero la prioridad en materia antiterrorista fue durante todo ese tiempo la lucha contra ETA.

El despertar tardío a la alarmante realidad del yihadismo global ha tenido como consecuencia que este haya jugado inicialmente con ventaja ya que es necesario un lapso temporal antes de que las agencias de seguridad de un país desarrollen capacidades específicas para combatirlo. En el campo concreto de la inteligencia contar con fuentes de obtención de inteligencia humana, de procesamiento de información (por ejemplo traductores), o con suficientes analistas especializados requiere siempre varios años de preparación e inversión. Se trata de capacidades que no se improvisan.

Por otra parte dentro del tema general del yihadismo también es preciso establecer prioridades concretas en función de la situación particu-

16 Omar Guendouz, Les soldats perdus de l'Islam: les reseaux français de Ben Laden, Paris, Éditions Ramsay, 2002.

17 Mohamed Sifaoui, La France, malade de l'islamisme: menaces terroristes sur l'Hexagone, Paris, Cherche Midi, 2002.

18 Juan AvilÉs, ¿Es Al-Qaida una amenaza para Europa?, Documento de Trabajo, Real Instituto Elcano, 16 de julio de 2002. Disponible en web: http://www.realinstitutoelcano.org/documentos/7.asp. 
lar de cada país. A ello puede ayudar conocer el tipo actividades que han desempeñado hasta ese momento las redes yihadistas detectadas en su territorio, los países de procedencia de sus integrantes, si han contado o no con apoyo local o de asociaciones con vínculos en el extranjero, el mapa de las comunidades islámicas presentes en el país, etc. Como los medios de inteligencia son habitualmente limitados conviene escoger con acierto las líneas de investigación más relevantes.

\subsection{Fase de Obtención}

Entre los diversos sistemas de obtención de información hay tres que son básicos cuando el objeto de interés es el terrorismo yihadista:

a) Inteligencia de señales (SIGINT). El yihadismo es capaz de actuar a escala global gracias al soporte que le proporciona la revolución en las tecnologías de la información. El abaratamiento de los costes de comunicación, la posibilidad de establecer contacto desde prácticamente cualquier lugar y de obtener información en tiempo real plantea grandes ventajas a estas redes. Son muy numerosos los ejemplos que demuestran la importancia que tiene para los yihadistas el empleo de frecuente de teléfonos móviles, correo electrónico, chat y mensajería instantánea en el desarrollo de actividades relacionadas con su causa ${ }^{19}$. No cabe duda de que la globalización de las comunicaciones es un poderoso multiplicador de fuerza para estos grupos.

Por otra parte, además de para coordinar sus acciones, los yihadistas también utilizan los sistemas de comunicación (y muy en especial todos aquellos que se utilizan en internet) para crear la identidad virtual de la comunidad de creyentes/muyahidines ${ }^{20}$. Mediante páginas web y listas de distribución de correo electrónico se mantienen informados de la situación de los yihadistas en otros lugares del planeta, comentan las noticias de actualidad desde su peculiar visión del mundo, y se apoyan unos a otros ${ }^{21}$. De esta manera se generan y mantienen lo que Manuel Castells

19 Rohan Gunaratna, Inside Al Qaeda. Global Network of Terror, New York, Columbia University Press, 2002.

${ }^{20}$ Gary R. Bunt, Islam in the Digital Age. E-Jihad, Online Fatwas and Cyber Islamic Environments, London, Pluto Press, 2003, pp. 67-111.

${ }^{21}$ Middle East Media Research Institute, «Islamist Websites and Their Hosts Part I: Islamist Terror Organizations» Special Report - No. 31 - Jihad and Terrorism Studies, July 16, 2004. Disponible en: http://www.memri.org/jihad.html. 
denomina oasis de identidad e identidades de resistencia ${ }^{22}$ que no circunscriben a un grupo concreto de un país sino que son compartidas por redes sociales transnacionales. Esas identidades accesibles por internet no sólo sirven para reforzar la decisión de los que ya pertenecen a los círculos yihadistas, sino que también mediante la difusión de ese tipo de contenidos propagandísticos están logrando el reclutamiento de nuevos adeptos, tal como reconoció en noviembre de 2004 el coordinador antiterrorista de la UE, Gijs de Vries ${ }^{23}$.

De esta manera los medios de obtención de Inteligencia de Señales pueden jugar un papel destacado en la interceptación de las comunicaciones de radicales y en el seguimiento de quienes frecuentas los espacios virtuales yihadistas. También pueden alertar sobre la existencia de dichos lugares web y aconsejar su bloqueo. Pero la SIGINT se encuentra con dos obstáculos en esta materia, por un lado los límites legales que garantizan la privacidad de las comunicaciones, que pueden ser removidos con autorización judicial en caso de que existan sospechas fundadas sobre una determinada persona. Por otro, y es el más importante, con el gigantesco volumen de información que circula a través de internet y de las líneas telefónicas, y con la dificultad de seguir a sujetos que cambian con frecuencia de tarjeta de móvil o de dirección de correo electrónico. A todo ello hay que sumar además el empleo de idiomas extranjeros y de variantes dialectales que dificultan enormemente la fase de procesamiento de la información obtenida. Como consecuencia de todos estos factores, la revolución en las tecnologías de la información va a continuar siendo una baza a favor de los yihadistas, antes que una oportunidad para las agencias a la hora de monitorizar sus actividades. La SIGINT será por tanto una vía de obtención de información útil pero subsidiaria en relación con otras fuentes.

b) Inteligencia humana (HUMINT). Por las características que se han descrito en el epígrafe 1.3. de este artículo resulta evidente la importancia crucial que adquiere esta vía de adquisición de información en el caso del terrorismo en general y especialmente del yihadista.

La información relevante que manejan estos grupos se limita a un círculo restringido de personas que componen la red. A través de individuos que frecuentan entornos islamistas radicales es posible conocer el grado de peligrosidad de determinados sujetos y a aquellas personas con los

${ }^{22}$ Manuel Castells, The power of identity, Malden, Blackwel, 2004, p. 8.

23 El País, 16 de noviembre de 2004. 
que estos mantienen relación. Sin embargo, obtener para obtener detalles sustanciales sobre sus planes o conocer el tipo de contactos internacionales con que cuentan requiere un nivel de proximidad y confianza que exige considerables dosis de tiempo y de riesgos personales. Por tanto esta área constituye una de las principales prioridades en materia de obtención. A pesar de su dificultad, a largo plazo es la que puede deteriorar más sensiblemente la capacidad operativa de las redes yihadistas. Las razones son dos. Por un lado permite conseguir información de gran calidad sobre la composición, modo de actuar y planes de estos grupos. Y, por otro, genera psicosis de infiltración en las redes yihadistas, obligándoles a aumentar las medidas de seguridad interna y a cerrarse sobre ellas mismas, con lo que sus oportunidades de reclutar nuevos adeptos y de coordinarse con otras personas se ve considerablemente mermadas.

La diferencia étnica entre estas redes y la población autóctona de los países occidentales puede ser salvada mediante el reclutamiento de potenciales confidentes entre las comunidades inmigrantes de donde proceden también los yihadistas. La experiencia de esta última década demuestra que los islamistas radicales captan a sus seguidores en esos colectivos ${ }^{24} \mathrm{y}$, por ello, la presencia de colaboradores de los servicios en dichos entornos puede facilitar la infiltración de las redes de la yihad global.

$\mathrm{Al}$ mismo tiempo, la toma de conciencia sobre peligro que supone este terrorismo para la convivencia intercultural por parte de los miembros de las comunidades islámicas, y la buena relación de los servicios con personas clave de dichas comunidades, también puede proporcionar información valiosa. En ocasiones se tratará de comentarios sobre individuos que despiertan sospechas, del perfil de recién llegados procedentes de zona de conflicto, o de detalles sobre grupos en los que se difunde una visión radical del islam. Aunque no se trate de información decisiva, sí que puede facilitar el comienzo de investigaciones más profundas $\mathrm{y}$, al mismo tiempo, evitar que los yihadistas puedan hacer proselitismo abiertamente en esos entornos.

c) Cooperación internacional. La importancia de esta vía de obtención en la lucha contra el yihadismo se deriva principalmente de dos razones.

Por una parte, porque el yihadismo global no tiene fronteras. Las detenciones de redes en Europa demuestran que durante el desarrollo de

${ }^{24}$ Robert S. LeIKen, Bearers of Global Jihad? Immigration and National Security after 9/11, Washington, DC, The Nixon Center, 2004, p. 8-9. 
sus tareas esas personas suelen mantener contacto con otros yihadistas en el exterior del país. A través de la cooperación internacional existen más probabilidades de descubrir las redes presentes en el propio territorio, seguir sus actividades y darles la importancia que se merece en cada caso. La gravedad que representa el terrorismo islamista supone, al mismo tiempo, un poderoso incentivo para el intercambio de información.

Por otro lado, porque la cooperación con las países donde surgieron estos movimientos y de donde procede una proporción muy considerable de sus integrantes resulta también de gran ayuda para obtener inteligencia de calidad. Las redes yihadistas que actúan en Occidente se extienden en la mayor parte de los casos a otros países de mayoría musulmana en el norte de África, Oriente Medio, Asia Central y Asia Pacífico, en función de la nacionalidad mayoritaria de cada una de ellas. A la vez, algunos de esos países han tenido desde hace años informadores en la diáspora migratoria en Europa con el fin de controlar la disidencia política y los grupos radicales, y es probable que mantengan esa infraestructura informativa en la actualidad. Por todas esas razones la información què estos servicios proporcionen puede ser muy útil para el conocimiento de las actividades yihadistas en todo el planeta.

\subsection{Fase de Elaboración}

La complejidad del fenómeno del yihadismo global supone un auténtico reto para los analistas de inteligencia. Por un lado, porque como ya se ha explicado en el primer epígrafe del artículo, se trata de un terrorismo de naturaleza esencialmente distinta a los que han atormentado Europa desde el fin de la Segunda Guerra Mundial. Su inspiración ideológica, su cálculo racional y su articulación organizativa exigen un cambio de mentalidad en aquellos que quieran comprenderlo. Si siempre es conveniente que el analista haga el esfuerzo de ver la realidad como la contempla su objeto de estudio ${ }^{25}$, en el caso del yihadismo resulta particularmente necesario con el fin de comprender sus acciones y, en la medida de lo posible, anticiparse a ellas. Por tanto, la inteligencia sobre terrorismo islamista no debe limitarse a la de carácter meramente operativo (sobre composición, interconexión y actividades de redes) sino

${ }^{25}$ Mark Lowenthal, Intelligence. From Secrets to Policy, Washington, CQ Press, 2003, pp. 80-81. 
a analizar en profundidad los factores ideológicos, políticos y sociales que de algún modo alimentan la hidra terrorista ${ }^{26}$.

Pero además de provenir de un universo cultural extraño para la mayor parte de los especialistas en inteligencia, el terrorismo islamista plantea otro problema analítico por el carácter descentralizado, polifacé tico y autónomo de muchas de las redes de la yihad global. Ya hemos constatado que no existe un órgano central o una estructura jerarquizada que se asemeje a lo que en la Guerra Fría fueron los cuarteles generales de los servicios adversarios, sus gobiernos o sus estados mayores y las distintas divisiones administrativas que dependían de ellos. Tampoco responde al modelo de organización burocrática que seguían grupos terroristas como por ejemplo ETA. Por tanto, el análisis sobre estos grupos debe ser mucho más fino, evitar las generalizaciones o tratar a todos los actores yihadistas como si respondiesen a un único perfil

Por otra parte, los análisis de inteligencia sobre yihadismo también deben asesorar sobre la evolución del fenómeno. Los servicios suelen procurar que la inteligencia y el apoyo a la toma de decisiones políticas estén enfocados al futuro. En el caso del yihadismo esa práctica resulta particularmente conveniente, ya que puede alertar sobre los efectos contraproducentes de algunas políticas antiterroristas. El terrorismo islamista obtiene fuerza del sentimiento de agravio y humillación de determinados sectores del mundo musulmán (tanto en los países donde son mayoría como en las comunidades inmigradas), del choque de valores que propicia el mayor contacto entre culturas, y de la existencia de conflictos abiertos, que generan radicalización en los directamente afectados y en algunos que se sienten identificados con ellos (Palestina, Irak y Asia Central) ${ }^{27}$. Por ese motivo, conviene que los servicios aporten una valoración profunda de las posibles consecuencias en la fase previa a la toma de decisiones en materia de antiterrorismo.

La mejora de la capacidad de análisis requiere por parte de los servicios varias condiciones: un notable esfuerzo en la formación previa y permanente de los analistas, cercanía de estos con los que desarrollan tareas de obtención en esta área, continuidad temporal de los analistas en

26 Un libro interesante en este sentido escrito por un analista de alto nivel de la Agencia Central de Inteligencia norteamericana es AnONYMous, Through Our Enemies Eyes. Osama Bin Laden, Radical Islam, and the Future of America, Washington, Brassey's Inc, 2002.

27 Farhad Josrojavar, Los nuevos mártires de Alá, Madrid, Ediciones MR, 2003, pp.238-239. 
puestos relacionados con dicha temática, y contacto de estas personas con otros especialistas externos al servicio que trabajen sobre temas que tengan alguna vinculación con el yihadismo global (por ejemplos académicos e investigadores expertos en islamismo, relaciones internacionales, inmigración, religión, movimientos sociales, etc). Además también resulta muy conveniente el intercambio de opiniones con analistas de las otras agencias de seguridad nacionales (policiales y militares) que trabajen de alguna manera el mismo objeto de estudio. Aunque es difícil que, por razones de seguridad y de cultura profesional, las agencias de inteligencia de un mismo país compartan información relacionada con fuentes y obtención, sí es más probable que se genere esa cooperación en la fase de análisis, a través de seminarios internos o grupos de trabajo en el marco de la Comunidad de Inteligencia ${ }^{28}$. Todas estas medidas favorecen la elaboración de análisis competitivos y. la comprensión global de un fenómeno de enorme complejidad.

d) Fase de Difusión. En ocasiones la fase de difusión es el talón de Aquiles del ciclo de inteligencia y, en el caso concreto del terrorismo yihadistas, corre mayores riesgos de serlo como consecuencia del número de agencias estatales implicadas en su prevención y lucha. Una de las conclusiones que se extrae del informe de la Comisión Nacional del 11-S es la existencia de graves carencias de las diferentes agencias norteamericanas en la difusión de la información y análisis sobre Al-Qaida, particularmente entre el FBI y la CIA en investigaciones sobre personas que estuvieron implicadas en los atentados, y entre estos servicios y las agencias federales responsables de inmigración y seguridad aérea ${ }^{29}$.

Por esta razón es clave la existencia y buen funcionamiento de la comunidad de inteligencia, entendida como la estructura de trabajo permanente entre los distintos organismos del Estado relevantes desde el punto de vista de la inteligencia y no sólo el conjunto agregado de estos. La circulación adecuada de los análisis por los diferentes departamentos de la Administración constituye un requisito indispensable para que se obtenga el máximo provecho del esfuerzo realizado en las fases anteriores del ciclo de inteligencia.

28 Francisco GalVACHE, «La Inteligencia Compartida», Instituto Español de Estudios Estratégicos, Estudios sobre Inteligencia: Fundamentos para la Seguridad Nacional, Madrid, Ministerio de Defensa, 2004, pp. 171-172.

${ }^{29}$ National Commission on Terrorist Attacks, «The 9/11 Commission Report: Final Report of the National Commission on Terrorist Attacks Upon the United States, pp. 79-83. 


\section{El CNI y la lucha contra el terrorismo yihadista}

Los sucesivos servicios de inteligencia españoles (SECED, CESID y actualmente $\mathrm{CNI}$ ) han dedicado desde hace décadas numerosos esfuerzos y recursos a la obtención de información y elaboración de inteligencia sobre terrorismo nacional. Como consecuencia los servicios de inteligencia españoles cuentan con más experiencia en materia antiterrorista que muchos de sus iguales extranjeros. El CNI dedica un área completa de la Dirección General de Inteligencia al fenómeno terrorista en su dimensión interior y exterior. El terrorismo exterior coincide básicamente con el terrorismo islamista ${ }^{30}$.

Como es sabido, los miembros del CNI no tienen estatus de agentes de la autoridad y por tanto no pueden llevar a cabo detenciones ni operaciones de neutralización de terroristas. La labor del CNI en materia de terrorismo no está orientada a instruir procesos penales, sino a proporcionar análisis al Gobierno sobre el tema en cuestión. Para ello el Centro cuenta con medios de obtención propios y en sus análisis integra también la información relevante que le transmiten las agencias policiales ${ }^{31}$.

El terrorismo islamista no es un tema nuevo para el Centro. Antes de los atentados de Madrid las agencias de seguridad españolas habían llevado a cabo más de sesenta detenciones de personas vinculadas a redes yihadistas. Las primeras se efectuaron en 1995 y su número se incrementó a partir del otoño de 2001. En los años 2002-2003 varias de esas detenciones fueron de personas que estaban preparando atentados terroristas en España y Francia ${ }^{32}$. Al tratarse de una materia reservada no es posible conocer hasta qué punto las informaciones obtenidas por el Centro y sus análisis fueron decisivos en la desarticulación de esas redes. No obstante, los servicios de inteligencia trabajaron sobre dicha cuestión desde que se detectó la presencia de redes yihadistas en nuestro país.

Según se ha sabido con posterioridad a los atentados del 11 de marzo de 2004, fue el CNI el que obtuvo información más relevante sobre el ar-

30 Sobre este tema puede consultarse en Centro Nacional de Inteligencia, «Servicios de Inteligencia y lucha contra el terrorismo", Carlos DE CUETO y Javier JORDÁN (Eds.) Respuestas a nuevos desafios de seguridad, Granada, Comares, 2003, pp. 25-36.

${ }^{31}$ Comparecencia de D. Jorge Dezcallar, ex-director del Centro Nacional de Inteligencia, en la Comisión de Investigación del Congreso de los Diputados sobre los atentados del 11 de marzo de 2004, 19 de julio de 2004. Disponible en http://www.congreso.es.

32 Comparecencia de D. Mariano Rayón, Jefe de la Unidad Central de Información Exterior del Cuerpo Nacional de la Policía, en la Comisión de Investigación del Congreso de los Diputados sobre los atentados del 11 de marzo de 2004, 7 de julio de 2004 . 
gelino Allekema Lamari, muy posiblemente la persona que lideró la preparación de las acciones terroristas. En noviembre de 2003, el Centro alertó que esta persona pretendía atentar en nuestro país y recomendó su inmediata detención ${ }^{33}$. Semanas antes del 11-M, el CNI repartió fotografías de Lamari en diversas oficinas de correos de Madrid y Valencia con el fin de que avisaran a la policía o al Centro, en caso de que el argelino se presentara en alguna de ellas para enviar dinero a través de giro postal a antiguos miembros del GIA en prisión ${ }^{34}$.

Con posterioridad a los atentados de Madrid ha aumentado la atención sobre la amenaza del yihadismo y se han incrementado los medios de inteligencia destinados a la lucha contra el yihadismo en las tres agencias de seguridad con competencias en la materia. Concretamente, para la Guardia Civil y el Cuerpo Nacional de Policía se ha previsto triplicar el número de agentes de las unidades centrales de información, antes de diciembre de 2005, y mejorar sustancialmente sus medios materiales. De acuerdo con el artículo 7 de la Ley del Centro Nacional de Inteligencia, los detalles sobre la estructura y los miembros del Centro son de carácter secreto y, por tanto, no es posible conocer la entidad de los medios que ha venido dedicando a la obtención de información y análisis del terrorismo islamista, ni el aumento que van a experimentar en los próximos años. El único dato disponible es que en 2004 el presupuesto del Centro creció un 17,4\% y en 2005 un 17,1\% respecto al año anterior $^{35}$. Entre otras razones, ese incremento está respondiendo a la necesidad de dotar económicamente una ampliación sustancial de las plantillas en todos los niveles.

Esta mejora de medios materiales y humanos también se está beneficiando desde el año 2002 del marco legal que le proporcionan las leyes 11/2002, reguladora del Centro Nacional de Inteligencia y de la ley Orgánica $2 / 2002$, reguladora del control judicial previo del Centro Nacional de Inteligencia, que crean un marco legal a la actuación del Centro. Sin él, la eficacia y la cobertura jurídica de las actividades necesarias para el ciclo de inteligencia quedarían en entredicho.

La importancia de todas estas mejoras es indudable, pero el reto más ambicioso que tienen los servicios de inteligencia españoles consiste en la creación de una auténtica Comunidad de Inteligencia, que como ya se ha comentado en el epígrafe anterior resulta indispensable en la lucha con-

33 El Pais, 19 de septiembre de 2004.

34 El Pais, 7 de noviembre de 2004.

35 El Mundo, 28 de septiembre de 2004. 
tra el yihadismo global. La cooperación antiterrorista antes del 11 de marzo se realizaba a través de reuniones de carácter semanal que mantenían responsables de información de cada una de las tres agencias con el Secretario de Estado de Seguridad (dependiente del Ministerio del Interior). Otra vía de coordinación era de carácter informal, a través de contactos y consultas personales entre agentes de las distintas agencias que trabajaban en temas similares ${ }^{36}$. Aunque esta estructura de cooperación pudiera resultar válida, de hecho no aseguraba que la información tratada por los responsables del más alto nivel fluyera después a los escalones inferiores de cada una de las agencias. Al mismo tiempo, la eficacia del contacto informal entre especialistas quedaba también sujeta al talante personal de los que ocuparan ese tipo de puestos.

Después de los atentados de Madrid, y con el fin de potenciar y fortalecer la cooperación de inteligencia en materia de terrorismo, se ha creado el Centro Nacional de Coordinación Antiterrorista (CNCA). No se trata de una nueva agencia de seguridad y, por tanto, no tiene funciones de carácter operativo, sino de intercambio de información y apoyo a las investigaciones de cada una de las agencias. Concretamente las tareas asignadas son las siguientes ${ }^{37}$ :

- Obtención de información y creación de bases de datos. La información provendrá de la que obtengan, y tengan ya acumulada en materia de terrorismo, el Cuerpo Nacional de Policía, la Guardia Civil y el Centro Nacional de Inteligencia. Además, incorporará la información que se logre mediante el acceso a las bases de datos del Grupo de cooperación policial sobre terrorismo, del sistema Interpol, de la red Bureau des liaisons, del tercer pilar de la Unión Europea; y a cualquier otra base de datos que se considere de relevancia.

- Análisis y evaluación de dicha información y elaboración de informes periódicos sobre la amenaza terrorista.

- Coordinación operativa de las acciones contra el terrorismo que realicen las agencias con el fin de incrementar la eficacia y evitar que se

36 Comparecencia de D. Faustino Álvarez, Jefe de la Unidad Central Especial de la Guardia Civil, en la Comisión de Investigación del Congreso de los Diputados sobre los atentados del 11 de marzo de 2004, 7 de julio de 2004. Disponible en http://www.congreso.es.

37 Intervención del Ministro de Interior, D. José Antonio Alonso, en la Comisión de Interior del Congreso de los Diputados, 24 de mayo de 2004. Disponible en http://www.congreso.es. 
produzcan interferencias entre unas y otras. Cada agencia mantendrá su autonomía operativa y llevará a cabo las operaciones que se le asignen. El CNCA como tal no realizará operaciones antiterroristas.

El puesto de director del CNCA está ocupado, por rotación de dos años, por un miembro del Cuerpo Nacional de Policía o de la Guardia Civil $^{38}$. Consta actualmente de una plantilla de 18 agentes de la Policía, 18 de la Guardia Civil y 5 del Centro Nacional de Inteligencia. A ellos hay que sumar un número reducido de traductores y personal de apoyo. Momentáneamente el Centro tiene su sede en un cuartel del Cuerpo Nacional de Policía en Canillas (Madrid), donde se encuentra ubicada la Unidad Central de Información, pero está prevista la construcción de una sede propia.

La creación del CNCA constituye un paso gran interés en la mejora de la cooperación interagencias, pero para que sea efectivo debe ir también acompañado de un cambio cultural entre los protagonistas de la cooperación a todos los niveles. La creación de nuevas instituciones no constituye una garantía de que estas vayan a lograr sus fines, tal como lo demuestra el caso norteamericano, donde también existía un centro de coordinación antiterrorista desde mediados de los años 80 que no fue capaz de evitar los errores de coordinación de inteligencia ante los atentados del Washington y Nueva York ${ }^{39}$.De ahí la importancia que adquiere la creación y correcto desarrollo del conjunto de la comunidad de inteligencia española, ya que es en ese marco donde el CNCA adquiere pleno sentido.

La gran tarea de poner en marcha la Comunidad de Inteligencia afecta a todas las agencias de seguridad y también a los altos cargos políticos que las dirigen. En definitiva es el Gobierno el responsable último de la seguridad de los ciudadanos, y es además quien cuenta con el liderazgo y la autoridad necesarios para llevar a cabo los cambios políticos y legales que resulten precisos para la creación de la Comunidad.

38 Acuerdo del Consejo de ministros del 28 de Mayo de 2004, por el que se crea el Centro Nacional de Coordinación Antiterrorista. Disponible en http:/www.la-moncloa.es/.

${ }^{39}$ National Commission on Terrorist Attacks, «The 9/11 Commission Report: Final Report of the National Commission on Terrorist Attacks Upon the United States, p. 92. 